\title{
Terapia ocupacional en tiempos de pandemia: seguridad social y garantías de un cotidiano posible para todos ${ }^{1}$
}

Occupational therapy in times of pandemic: social security and
guaranties of possible everyday life for all

Terapia ocupacional em tempos de pandemia: seguridade social e garantias de um cotidiano possível para todos

Ana Paula Serrata Malfitano ${ }^{2}$

Daniel Marinho Cezar da Cruz ${ }^{3}$

Roseli Esquerdo Lopes ${ }^{4}$

Recibido: 25 de mayo 2020 - Aceptado: 10 de agosto 2020

Malfitano, A.P.S., Cruz, D.M.C. y Lopes, R.E. (2020). Terapia ocupacional en tiempos de pandemia: seguridad social y garantías de un cotidiano posible para todos (traducción). Revista Ocupación Humana, 20 (1), 118-123. https://doi. org/10.25214/25907816.950

La pandemia causada por el SARS-CoV-2 ha demandado a todas las profesiones repensar y restructurar sus roles para lidiar con la COVID-19, asegurando y reafirmando la importancia de sus contribuciones frente a la complejidad de las

\footnotetext{
1 Este texto fue publicado originalmente por sus autores, como editorial, en portugués e inglés, en el vol. 28 n. 2 de Cadernos Brasileiros de Terapia Ocupacional (Malfitano et al., 2020). Disponible en: https://doi.org/10.4322/2526-8910.ctoed22802

${ }^{2}$ Terapeuta ocupacional. Magíster en Educación. Doctora en Salud Pública. Docente, Universidade Federal de São Carlos. Editora, Cadernos Brasileiros de Terapia Ocupacional/ Brazilian Journal of Occupational Therapy. São Carlos, Brasil. anamalfitano@ufscar.br iD https://orcid.org/0000-0002-05023194).

${ }^{3}$ Terapeuta ocupacional. Magíster y doctor en Educación Especial. Docente Visitante, Wrexham Glyndwr University. Wrexham, Reino Unido. Docente, Universidade Federal de São Carlos. Editor, Cadernos Brasileiros de Terapia Ocupacional/Brazilian Journal of Occupational Therapy. cruzdmc@gmail.com iD https://orcid.org/0000-0002-4708-354X

${ }^{4}$ Terapeuta ocupacional. Especialista en Salud Mental. Magíster y doctora em Educación. Docente, Universidade Federal de São Carlos. Editora, Cadernos Brasileiros de Terapia Ocupacional/Brazilian Journal of Occupational Therapy. São Carlos, Brasil. relopes@ufscar.br iD https://orcid.org/0000-00019572-4586).
} 
exigencias del momento que vivimos. La Terapia Ocupacional ha venido participando de este proceso a través de diferentes iniciativas, centrando la atención en el cotidiano de las personas, quienes, en sus diferentes modos de vida, tienen en común la necesidad del distanciamiento social impuesto por la transmisión acelerada del virus y por las debilidades e imposibilidades de los sistemas de vigilancia sanitaria y epidemiológica de muchos países. No obstante, consideramos que nuestro rol es fundamental en el ámbito de la seguridad social, en consonancia con las políticas sociales y, especialmente, abordando importantes situaciones relacionadas con las inequidades sociales que impactan la vida de las personas, los grupos y las comunidades con quienes trabajamos, especialmente en Brasil.

La Federación Mundial de Terapeutas Ocupacionales - WFOT lanzó su posicionamiento público sobre la respuesta de la profesión a la pandemia de COVID-19, señalando el profundo impacto en la vida, la salud y el bienestar de las personas, las familias y las comunidades alrededor del mundo. La Federación hace énfasis en el papel de las y los terapeutas ocupacionales en la vida diaria de los sujetos, en los significados y propósitos de las actividades cotidianas en sus vidas. De esta forma, resalta la relevancia del desarrollo de estrategias para ayudarles a asumir sus "ocupaciones" (como se mencionan en el documento original). En particular, subraya la atención a los problemas de salud mental resultantes de la pandemia, el acceso a tecnologías de asistencia y, especialmente, la telesalud como nuevo formato de trabajo (World Federation of Occupational Therapists -WFOT, 2020).

En este mismo sentido, el Consejo Federal de Fisioterapia y Terapia Ocupacional - COFFITO (2020a), por medio de la Resolución no. 516 del 20 de marzo de 2020, reglamentó la telesalud como una modalidad posible de trabajo para dar continuidad a la atención de terapeutas ocupacionales y fisioterapeutas con algunos grupos de la población. Se han creado nuevas modalidades de cuidado (Malfitano y Sakellariou, 2019) para garantizar que no se interrumpa la atención a grupos específicos. La Asociación Brasileña de Terapeutas Ocupacionales -ABRATO (2020) manifestó su preocupación por las prácticas y las condiciones de trabajo en el escenario de la pandemia; así mismo, señaló las contribuciones de terapeutas ocupacionales y declaró su presencia en la primera línea de frente en el Sistema Único de Salud, el sistema privado de salud, el Sistema Único de Asistencia Social y, también, en instituciones del tercer sector, llevando a cabo proyectos sociosanitarios, culturales y humanitarios.

Enfocándose en la vida cotidiana de las personas, la Asociación Australiana de Terapeutas Ocupacionales -OTA (2020) publicó la guía denominada La vida normal se ha interrumpido: manejando la ruptura causada por la COVID-195, la cual fue traducida al portugués por la Asociación Cultural de los Terapeutas Ocupacionales del Estado de Paraná -ACTOEP (2020) bajo el título Orientaciones prácticas para rutinas sanas: aprendiendo a lidiar con los cambios de rutina debidos al CO-

\footnotetext{
${ }^{5}$ Normal life has been disrupted: managing the disruption caused by COVID-19.
} 
VID-196. En ese documento se sistematiza información importante relacionada con la organización de la vida diaria en términos de productividad, autocuidado, recreación, ambiente, rutina y desempeño de diferentes roles ocupacionales. La guía ofrece recomendaciones prácticas para la realización de las actividades diarias en el aislamiento doméstico, así como orientaciones y sugerencias para el mantenimiento de la salud física y mental.

Considerando el locus de las acciones de Terapia Ocupacional, es decir, la vida cotidiana, las actividades, el hacer y las ocupaciones de los sujetos, se han producido algunos materiales dirigidos a grupos o temas específicos, tales como: salud mental (Universidade Federal de São Carlos, 2020a), autismo (Universidade Federal de São Carlos, 2020b), ergonomía (Conselho Federal de Fisioterapia e Terapia Ocupacional, 2020b), entre otros. Estas publicaciones se han escrito sin el enfoque en Terapia Ocupacional, pero con la participación o la colaboración de representantes de la profesión en su autoría.

Así, reconociendo la relevancia de todas esas iniciativas y contribuciones relacionadas con la ocupación y el aislamiento, igualmente reafirmamos la necesidad de que las y los terapeutas ocupacionales aborden la dimensión de la desigualdad social. Esto es importante, entre otras razones, porque las características del esparcimiento del virus y de la enfermedad en las comunidades empobrecidas de la periferia de las ciudades, por ejemplo en las favelas, ha traído consigo grandes desafíos.
Las indicaciones de "quedarse en casa" y mantener el distanciamiento social en este tipo de contextos se relaciona con la ausencia de garantías materiales para la supervivencia, en lugares en los que se ha naturalizado que la vida, a diario, está en riesgo (Associação Brasileira de Saúde Coletiva, 2020). Esta situación también se observa en grupos como las personas que viven en la calle, migrantes, refugiadas y prisioneras. Hay además otros efectos del aislamiento social, como el triste y alarmante aumento de la violencia doméstica (Vieira et al., 2020), entre otras situaciones. Es en este contexto que abogamos por la participación de terapeutas ocupacionales y otros profesionales, basada en la noción y en la defensa de la seguridad social.

La seguridad social está prevista en la Constitución Brasileña (1988), en el artículo 194, e involucra un conjunto de iniciativas dirigidas a asegurar los derechos relativos a la salud, el aseguramiento (pensiones y derechos de los trabajadores) y el bienestar o la asistencia social. La relevancia de este principio legislativo nacional está en determinar que solo mediante la integración de tales derechos sociales es posible lograr el derecho a la vida social para todos, en otras palabras, la salud requiere acciones de aseguramiento social que garanticen medios para la supervivencia, al menos de las y los trabajadores, independientemente de si tienen una enfermedad o envejecen; igualmente, se necesitan acciones de asistencia social para asegurar, a todas y todos los ciudadanos, el acceso a servicios sociales básicos. La seguridad social solo se realiza por

${ }^{6}$ Orientações práticas para rotinas saudáveis: aprendendo a lidar com as mudanças de rotina devido ao COVID-19. 
medio de políticas y programas sociales en los que esos tres sectores (salud, aseguramiento y asistencia social) estén presentes, y sus acciones y servicios se garanticen y estén disponibles para toda la ciudadanía. Es importante también destacar la relación con la educación, reglamentada por medio del artículo 205 de la Constitución, pues esta se conecta con otros derechos y sectores, y es posible que, a través de esa integración, los promueva.

Por lo tanto, precisamos también abordar el papel de las y los profesionales en el Sistema Único de Asistencia Social, en el Instituto Nacional de Seguridad Social, en los sistemas de prisiones y judicial, en las escuelas, en los diferentes sectores de acción territorial y comunitaria, y en organizaciones no gubernamentales de interés público. Más que nunca es preciso que usemos nuestros espacios, nuestras acciones y nuestras voces para problematizar lo que viene ocurriendo en la sociedad en términos de las inequidades en el acceso a los beneficios sociales esenciales para todas las personas. Si estamos en capacidad de mostrar esas brechas, podremos tener un mayor efecto en las vidas de muchas personas $y$, consecuentemente, posibilitar y enriquecer su vida cotidiana. En primera instancia, debemos abogar por la calidad de esa cotidianidad; con este fin, el desafío es hacer valer la centralidad de la seguridad social, así como otros aspectos del bienestar social como derecho y deber ciudadano del Estado y de la sociedad. De esta manera es posible comprender las dimensiones sociales del aislamiento o distanciamiento social (Bezerra et al., 2020) y defender nuestra participación en campañas o acciones fundamentadas en la solidaridad, asuntos indispensables en estos momentos de pandemia.
Tal defensa se vincula con el presupuesto de que, por medio de los derechos sociales, particularmente la seguridad social, podemos abordar la vida cotidiana, las actividades, el hacer y las ocupaciones de los diferentes sujetos, grupos y comunidades. Así, la defensa de las políticas públicas sociales, especialmente de la salud pública, la seguridad y la asistencia social, hace parte de los tiempos de pandemia que atravesamos y nos empuja más allá de la adaptación y la organización de la vida diaria, desafiándonos como terapeutas ocupacionales a tejer relaciones entre contextos, políticas y vidas.

Finalizamos afirmando que el trabajo de Terapia Ocupacional en la vida cotidiana de las personas solo se concreta en la defensa de la calidad de vida para todos y todas, considerando las potencias y diferencias que le dan significado. Si asumimos la lucha por reducir las desigualdades, esta necesariamente involucra defender la seguridad social y nuestro papel profesional en este campo. 


\section{Referencias}

Associação Brasileira de Saúde Coletiva [ABRASCO] (2020). Coronavírus nas favelas: "É difícil falar sobre perigo quando há naturalização do risco de vida". ABRASCO. https://www.abrasco.org.br/ site/outras-noticias/saude-da-populacao/coronavirus-nas-favelas-e-dificil-falar-sobre-perigo-quando-ha-naturalizacao-do-risco-de-vida/46098/

Associação Brasileira de Terapeutas Ocupacionais [ABRATO] (2020). Nota da ABRATO sobre a portaria do Ministério da Saúde $n^{\circ}$ 639, de 02 de abril de 2020. ABRATO. https://www.facebook.com/ abratonacional/

Associação Cultural de Terapeutas Ocupacionais do Estado do Paraná [ACTOEP]. (2020). Orientações práticas para rotinas saudáveis: aprendendo a lidar com as mudanças de rotina devido ao COVID-19. ACTOEP. https://www.facebook.com/actoep

Bezerra, A.C.V., Silva, C.E.M., Soares, F.R.G. y Silva, J.A.M. (2020). Fatores associados ao comportamento da população durante o isolamento social na pandemia de COVID-19. Ciência \& Saúde Coletiva. No prelo. https://preprints.scielo.org/index.php/scielo/preprint/view/123/173

Brasil. Presidência da República (1988). Constituição da República Federativa do Brasil de 1988. Diário Oficial [da] República Federativa do Brasil. http://www. planalto.gov.br/ccivil 03/constituicao/ constituicao.htm

Conselho Federal de Fisioterapia e Terapia Ocupacional [COFFITO] (2020a). Reso- lução $n^{\circ}$ 516, de 20 de março de 2020. Dispões sobre Teleconsulta, Telemonitoramento e Teleconsultoria. Diário Oficial [da] República Federativa do Brasil, Brasília. https://www.coffito.gov.br/ nsite/?p=15825

Conselho Federal de Fisioterapia e Terapia Ocupacional [COFFITO] (2020b). Orientações ergonômicas para trabalho: home office. Conselho Regional de Fisioterapia e Terapia Ocupacional da 15a. Região - CREFITO-15. https://www.coffito.gov.br/nsite/ wp-content/uploads/2020/04/20200326 ErgonomiaA.pdf

Malfitano, A.P.S., Cruz, D.M.C. y Lopes, R.E. (2020). Terapia ocupacional em tempos de pandemia: seguridade social e garantias de um cotidiano possível para todos/ Occupational therapy in times of pandemic: social security and guaranties of possible everyday life for all. Cadernos Brasileiros de Terapia Ocupacional, 28(2), 401-404. https://doi.org/10.4322/25268910.ctoED22802

Malfitano, A. P. S. y Sakellariou, D. (2019). Care and occupational therapy: what kind of care definition do we have? Cadernos Brasileiros de Terapia Ocupacional, 27(3), 681-685. http://dx.doi. org/10.4322/2526-8910.ctoarf1886

Occupational Therapy Australia [OTA] (2020). Normal life has been disrupted: managing the disruption caused by COVID-19. OTA. https://otaus.com.au/ publicassets/af469002-6f6a-ea11-9404005056be13b5/OT\%20Guide\%20COVID-19\%20March\%202020.pdf 
Universidade Federal de São Carlos [UFSCar] (2020a). Cuidando da saúde mental em tempos de coronavírus. Laboratório de Terapia Ocupacional e Saúde Mental La Follia. https://www.informasus.ufscar. br/wp-content/uploads/2020/04/coronavirus saudemental-2.pdf

Universidade Federal de São Carlos [UFSCar]. (2020b). Autismo: em tempos de coronavírus como podemos ajudar? Laboratório de Terapia Ocupacional e Saúde Mental - La Follia. https://www.informasus. ufscar.br/wp-content/uploads/2020/04/ CONSCIENTIZAÇÃO-AUTISMO-E-CORONAVIRUS.pdf.

Vieira, P.R., Garcia, L.P. y Maciel, E.L.N. (2020). Isolamento social e o aumento da violência doméstica: o que isso nos revela? Revista Brasileira de Epidemiologia, 23, e200033. PMid:32321005. http://dx. doi.org/10.1590/1980-549720200033.

World Federation of Occupational Therapists [WFOT] (2020). Public statement - Occupational Therapyresponse to the COVID-19 pandemic. WFOT. https://www. wfot.org/about/public-statement-occupational-therapy-response-to-the-covid-19-pandemic\#entry:22326 